\title{
LA CODIFICACIÓN DE LOS DERECHOS EN LA CONSTITUCIÓN EUROPEA*
}

\author{
POR \\ TANIA GROPPI \\ Catedrática de Derecho Constitucional \\ Universidad de Siena
}

\section{INTRODUCCIÓN: PERO ENTONCES ES NIÑA! LA CENTRALIDAD DE LOS DERECHOS FUNDAMENTALES EN LA CONSTITUCIÓN EUROPEA}

Mucho se ha discutido, y continuará discutiéndose en Europa, sobre la naturaleza del texto firmado en Roma el 29 de octubre de 2004 por los representantes de los 25 Estados miembros, y sucesivamente sometido a un trabajoso proceso de ratificación. "¡Es niño!» (o sea, un Tratado), fueron las primeras palabras del vicepresidente de la Convención europea Giuliano Amato, comentando el texto que se acababa de dar a luz, en junio de 2003. Sin embargo, precisó a continuación que él hubiera preferido una niña (o sea, una Constitución).

Tal dilema representa el fundamento de un problema más amplio, con el cual debe enfrentarse la doctrina iuspublicística europea. La

* El texto reproduce, con algunas actualizaciones, la conferencia dictada el 17 de febrero de 2005 en el ámbito del seminario sobre "La Constitución europea" organizado por el Instituto de Investigaciones Jurídicas de la UNAM, en la Ciudad de México. Traducción del italiano al español realizada por Carlos Vidal Prado, Profesor Titular de Derecho Constitucional, UNED, Madrid. 
Unión Europea, en efecto, hace ya años que no deja de sorprender a los juristas, que encuentran todavía serias dificultades para encasillar sus institutos dentro de las categorías tradicionales. Temas como la naturaleza de la Unión (¿organización internacional, supranacional, confederación, Estado federal?), el proceso constituyente (¿se puede hablar de un proceso constituyente en ausencia de un pronunciamiento popular?), la Constitución europea (¿Tratado? ¿Constitución? Y, más todavía, ¿es posible una Constitución sin Estado?), el demos europeo (o, más bien, ¿los demoi europeos?), apasionan y dividen a los estudiosos, imponiéndoles un replanteamiento sobre el complejo del jus publicum europeum (baste llamar la atención sobre los nombres de algunos de los protagonistas del debate: Dieter Grimm, Jürgen Habermas, Joseph Weiler).

Sin querer afrontar aquí un tema tan complejo, es suficiente señalar que la presencia, en el "Tratado por el que se establece una Constitución para Europa" (que denominaremos, de ahora en adelante, más brevemente, "Constitución europea»), de una parte II enteramente dedicada a los derechos fundamentales, que se sitúa junto a la parte I, en la que se contienen los principios y la organización de las instituciones, nos acerca a la noción de Constitución propia de la tradición constitucional de las democracias occidentales (Ziller, 2004). Según esta tradición, que se remonta al pensamiento ilustrado, las constituciones modernas deben responder a tres funciones fundamentales: a) el reconocimiento de los derechos de los ciudadanos; b) la organización de las relaciones entre gobernantes y gobernados; c) la protección de los derechos de los gobernados y de las atribuciones de los diversos poderes. Tales funciones están bien sintetizadas en el art. 16 de la Declaración de los derechos del hombre y del ciudadano de 1789, según el cual "Una sociedad en la que la tutela de los derechos no está garantizada, ni se establece la separación de poderes, no tiene una constitución".

Precisamente por esto, es particularmente significativo que la Convención europea haya aprobado la parte I y la parte II en la misma sesión, el 13 de junio de 2003: la "Constitución de los poderes" y la "Constitución de los derechos" marchan a la par, y contribuyen a determinar los contenidos que, según el constitucionalismo occidental, son propios de los textos que llamamos "constituciones". A una conclusión diversa se habría debido llegar quizá si en el seno de la Convención hubiese sido aprobada la propuesta del correspondiente grupo de trabajo, que solicitaba que se insertase en la Constitución simplemente una referencia a la Carta de los derechos (colocándola, por tanto, en un anexo). 
Debe añadirse que, según lo dispuesto por el art. I-6, tales contenidos constitucionales están presentes en un texto que se sitúa expresamente en una posición de supremacía sobre el derecho (todo el derecho, también constitucional) de los Estados miembros; un texto que puede ser modificado solamente a través de un procedimiento agravado de revisión (previsto en los arts. IV-443 y IV-444) y cuyas violaciones, por parte del derecho "derivado" de la Unión, pueden ser controladas por parte del Tribunal de Justicia (III-365). Están presentes, en otras palabras, todos los elementos que habitualmente sirven para identificar una "Constitución rígida".

La presencia de un catálogo de los Derechos constituye, a un tiempo, un punto cualificador de la Constitución (que nos conduce a considerarla como tal) y uno de los resultados más espectaculares del trabajo de la Convención, que en pocos años logró superar los vetos entrecruzados que habían impedido, en 1999, conferir eficacia vinculante a la Carta de Niza (así también Ziller, 2004). El centro de la controversia lo habían constituido los derechos sociales. Algunos gobiernos consideraban que la tutela de tales derechos contenida en la Carta de Niza era incompatible con el funcionamiento eficiente del mercado; otros, al contrario (sobre todo los escandinavos), sostenían que el reconocimiento de tales derechos era demasiado débil, y temían que eso les obligase a un redimensionamiento de su modelo de Estado social.

En otras palabras, la incorporación de la Carta de los Derechos a la Constitución no era un resultado obvio y que había que dar por supuesto: Ia declaración de Laeken del 15 de diciembre de 2001 se limitaba a plantear el problema, remitiendo la solución a la decisión de la Convención y, después, de la Conferencia intergubernamental.

Además de ser "decisivas", las disposiciones sobre los Derechos se encuentran también entre las más conocidas y estudiadas de toda la Constitución europea. Las normas de la parte II, en efecto, en la cual se contienen los Derechos fundamentales, reproducen, con pocas modificaciones, que señalaremos, las de la Carta de los Derechos fundamentales de la Unión Europea de 1999. Hasta el punto de que se ha insertado como anexo a la Constitución una Declaración, en su tiempo redactada por el Praesidium de la Convención que había elaborado la Carta de Niza, que contiene una suerte de interpretación auténtica. Esto nos permitirá retomar, al comentar esta parte de la Constitución, muchas de las consideraciones ya desarrolladas por la doctrina con relación a la Carta de Niza. Teniendo presente sin embargo el nuevo valor que adquieren las normas, en cuanto insertas en un texto vinculante, tanto para la UE como para los Estados miembros. 
Disposiciones sobre los Derechos, por lo demás, se contienen también en la parte I e incluso en el preámbulo de la Constitución. Lo cual pone de relieve que, más allá de su indudable valor normativo, los derechos fundamentales tienen también un elevado valor simbólico y desempeñan un papel central en la construcción de la identidad europea.

En el preámbulo, en efecto, se afirma que se toma inspiración en "la herencia cultural, religiosa y humanista de Europa, a partir de la cual se han desarrollado los valores universales de los derechos inviolables e inalienables de la persona humana, la democracia, la igualdad, la libertad y el Estado de Derecho". Se trata de una frase altamente controvertida, con relación, sin embargo, a un aspecto distinto, es decir, la voluntad de incluir en el texto, por parte de algunos sectores políticos y de grupos religiosos, una referencia a las raíces cristianas de Europa. Nadie, hasta donde yo conozco, ha cuestionado la referencia a los derechos inviolables de la persona humana.

En la parte I, después, título I, "Definición y objetivos de la Unión», el art. I-2 singulariza los "valores de la Unión». Éstos se definen así:

"La Unión se fundamenta en los valores de respeto de la dignidad humana, libertad, democracia, igualdad, Estado de Derecho y respeto de los derechos humanos, incluidos los derechos de las personas pertenecientes a minorías. Estos valores son comunes a los Estados miembros en una sociedad caracterizada por el pluralismo, la no discriminación, la tolerancia, la justicia, la solidaridad y la igualdad entre mujeres y hombres".

No se trata de una proclamación provista de mero valor simbólico, sino dotada, en diversos sentidos, de valor normativo.

Ante todo, el art. l-2 sirve como parámetro para medir el respeto de los valores comunes por parte de los Estados miembros, estando previsto un procedimiento sancionatorio en caso de violación (art. I-59). Además, sirve como criterio de admisibilidad en relación con los nuevos Estados miembros, que deben respetar los valores contenidos en tal artículo y ocuparse de promoverlos (art. l-58).

Finalmente, ha de tomarse en consideración que los valores del Unión figuran asimismo, en el sentido indicado por el art. I-3, entre sus objetivos (apartado 1).

Entre estos se encuentran, además, otros aspectos relacionados con los Derechos fundamentales. Por ejemplo, en el apartado 3 del mismo artículo se afirma que 
"La Unión obrará en pro del desarrollo sostenible de Europa basado en un crecimiento económico equilibrado y en la estabilidad de los precios, en una economía social de mercado altamente competitiva, tendente al pleno empleo y al progreso social, y en un nivel elevado de protección y mejora de la calidad del medio ambiente. Asimismo, promoverá el progreso científico y técnico. La Unión combatirá la exclusión social y la discriminación y fomentará la justicia y la protección sociales, la igualdad entre mujeres y hombres, la solidaridad entre las generaciones y la protección de los derechos del niño",

mientras en el apartado 4 se afirma que

«En sus relaciones con el resto del mundo, la Unión afirmará y promoverá sus valores y intereses. Contribuirá a la paz, la seguridad, el desarrollo sostenible del planeta, la solidaridad y el respeto mutuo entre los pueblos, el comercio libre y justo, la erradicación de la pobreza y la protección de los derechos humanos, especialmente los derechos de los niños, así como al estricto respeto y al desarrollo del Derecho internacional, en particular el respeto de los principios de la Carta de las Naciones Unidas".

El art. I-4, a su vez, regula las «libertades fundamentales y la no discriminación»:

"La Unión garantizará en su interior la libre circulación de personas, servicios, mercancías y capitales y la libertad de establecimiento, de conformidad con lo dispuesto en la Constitución».

El título II de la parte I, más adelante, está específicamente dedicado a los Derechos fundamentales y a la ciudadanía de la Unión.

El art. I-9 prevé lo siguiente:

«1. La Unión reconoce los derechos, libertades y principios enunciados en la Carta de los Derechos Fundamentales que constituye la Parte II.

2. La Unión se adherirá al Convenio Europeo para la Protección de los Derechos Humanos y de las Libertades Fundamentales. Esta adhesión no modificará las competencias de la Unión que se definen en la Constitución.

3. Los derechos fundamentales que garantiza el Convenio Europeo para la Protección de los Derechos Humanos y de las Libertades Fundamentales y los que son fruto de las tradiciones constitucionales comunes a los Estados miembros forman parte del Derecho de la Unión como principios generales".

El art. I-10 prevé que: 
«1. Toda persona que tenga la nacionalidad de un Estado miembro posee la ciudadanía de la Unión, que se añade a la ciudadanía nacional sin sustituirla.

2. Los ciudadanos de la Unión son titulares de los derechos y están sujetos a los deberes establecidos en la Constitución. Tienen el derecho:

a) de circular y residir libremente en el territorio de los Estados miembros;

b) de sufragio activo y pasivo en las elecciones al Parlamento Europeo y en las elecciones municipales del Estado miembro en el que residan, en las mismas condiciones que los nacionales de dicho Estado;

c) de acogerse, en el territorio de un tercer país en el que no está representado el Estado miembro del que sean nacionales, a la protección de las autoridades diplomáticas y consulares de cualquier Estado miembro en las mismas condiciones que los nacionales de dicho Estado;

d) de formular peticiones al Parlamento Europeo, de recurrir al Defensor del Pueblo Europeo, así como de dirigirse a las instituciones y a los órganos consultivos de la Unión en una de las lenguas de la Constitución y de recibir una contestación en esa misma lengua. Estos derechos se ejercerán en las condiciones y dentro de los límites definidos por la Constitución y por las medidas adoptadas en aplicación de ésta».

Estas extensas citas sirven simplemente para mostrar que la Constitución europea se basa sobre la garantía de los derechos fundamentales: éstos constituyen hoy el verdadero fundamento de la identidad europea.

Las páginas que siguen se orientarán a: a) verificar si se trata de una novedad (o en qué medida se trata de una novedad) respecto al "camino comunitario"; b) qué características reviste la codificación de los derechos realizada a través de la Constitución europea, en relación a las Cartas internacionales sobre los derechos y a las constituciones nacionales; c) cuáles pueden ser las consecuencias de tal codificación para el futuro de la Unión, en sus relaciones con los Estados miembros y con el Convenio Europeo para la salvaguarda de los Derechos del Hombre y de las libertades fundamentales, firmado en Roma el 4 de noviembre de 1950 (de ahora en adelante, CEDH).

\section{LOS DERECHOS FUNDAMENTALES EN LA UNIÓN EUROPEA: UNA CONSTRUCCIÓN JURISPRUDENCIAL}

Como ha sido puesto de relieve (Ziller 2004), todas las Constituciones de los Estados miembros de la Unión europea, al igual que las de 
los países candidatos, contienen de una u otra manera una declaración de los Derechos fundamentales. Incluso el Reino Unido, entre cuyos documentos constitucionales se sitúan, por lo demás, desde los orígenes, declaraciones de los derechos (piénsese en el Bill of Rights del 1689), se ha dotado recientemente, en 1998, de una Carta orgánica de los Derechos (Human Rights Act). Además, el CEDH ha sido ratificado por todos los Estados miembros de la UE.

El fundamento de las Comunidades europeas, en origen esencialmente económico, explica la ausencia de una declaración similar en los Tratados de París (Ceca) y de Roma (Cee y Euratom). Tal ausencia, por otra parte, no es una especificidad de los Tratados comunitarios: muchos tratados internacionales no se preocupan de la garantía de los derechos: en efecto, en el caso de que una organización internacional, o un Estado, al adaptarse a la obligación impuesta por un tratado, tuviese que violar un derecho "subjetivo", se desencadenarían los mecanismos "ordinarios" predispuestos para la garantía de los derechos por parte de los ordenamientos nacionales y por el internacional. En una primera lectura, por tanto, se consideraría "anómala» la evolución que al respecto ha vivido el ordenamiento comunitario, primero en vía jurisprudencial y, sucesivamente, en vía normativa.

Anómala al menos en parte. En efecto, se ha recordado ya que la exigencia que existía en el mismo origen del Tratado de Roma, la creación de un espacio único europeo, implicaba necesariamente la garantía de una serie de libertades fundamentales. Algunas de estas habían sido acogidas desde el origen de la construcción comunitaria: el derecho de los trabajadores a buscar trabajo en otro Estado miembro, (prohibiéndose, por tanto, las discriminaciones fundamentadas en la nacionalidad), la libre prestación de los servicios, la libre competencia, y la prohibición de abuso de una posición predominante. Tales libertades representan el instrumento de realización del mercado común, constituyendo el componente esencial del aparejo jurídico del propio mercado. Los Derechos fundamentales han sido progresivamente reconocidos como complemento indispensable del espacio único europeo, aunque todavía no sea homogéneo. Las diferencias de un Estado miembro a otro en el campo de la tutela de esta categoría de derechos podían llevar a poner en duda la misma existencia de un espacio único. La necesidad de una armonización en la garantía de tales derechos estaba destinada evitar el dumping social que puede verificarse como consecuencia de las legislaciones de los Estados que no reconocen las garantías mínimas a los trabajadores, desde el punto de vista de las remuneraciones, de las horas de trabajo, de la indemnización por despido, etc. (Gambino 2005). 
Como es conocido (Cartabia-Weiler 2000), a partir de los inicios de los años sesenta, el Tribunal de Justicia, en colaboración con los jueces nacionales, ha desarrollado una interpretación de los tratados constitutivos según la cual muchas disposiciones de los mismos, y también del derecho generado por las instituciones comunitarias, debían considerarse como dotadas de "efecto directo", entrando automáticamente a formar parte del derecho de cada Estado miembro. Pero no solamente eso. Las disposiciones mismas debían ser consideradas en posición de supremacía (primauté) respecto a todas las normas del ordenamiento nacional, comprendidas también, según la Corte de Luxemburgo, las constitucionales: normas nacionales que, en caso de conflicto con las comunitarias dotadas de efecto directo, debían ser inaplicadas. Como se ha afirmado brillantemente (por E. Stein, que escribía en 1981), "apartado en el país de las fábulas del Ducado del Luxemburgo y rodeado, hasta hace poco tiempo, de la benévola indiferencia por parte de los poderes constituidos y de los mass media, el Tribunal de Justicia ha modelado una arquitectura constitucional para un Europa de tipo federal».

Sin que podamos detenernos aquí sobre las razones de una semejante, e imprevista, evolución (se ha hablado de una "revolución judicial» para denominar esta construcción constitucional de naturaleza pretoriana), conviene subrayar que precisamente de ésta se deriva la exigencia de garantizar los Derechos fundamentales en el ámbito comunitario. ¿Cómo habría sido posible de otro modo afirmar el efecto directo y la primacía del derecho comunitario (o sea, de conferir un poder tan amplio a las instituciones de la UE), en ausencia de garantías normativas y jurisdiccionales? La consecuencia del efecto directo y de la primauté era la de excluir toda posibilidad de control sobre el derecho comunitario por parte de las instituciones de los Estados miembros, incluidos los Tribunales constitucionales. Añádase a esto el «déficit democrático" del sistema institucional comunitario. ¿Cómo podía esperarse que los Tribunales constitucionales de los Estados miembros dotados de Cartas de Derechos rígidas, pudiesen aceptar los principios del efecto directo y de la primauté sin asegurar que los derechos fundamentales serían adecuadamente protegidos en el ámbito del ordenamiento comunitario y que cada persona individual no tuviese ninguna de las garantías previstas por las Constituciones nacionales?

Si se examinan las principales resistencias avanzadas por los Tribunales constitucionales nacionales, los primeros entre todos el italiano y el alemán, a la primauté del derecho comunitario sobre las constituciones nacionales, se ve que dichas resistencias han venido dictadas sobre todo por la exigencia de poder contar con un nivel considerado 
como adecuado y suficiente de tutela de los derechos fundamentales (Groppi-Celotto 2004).

Frente a una afirmación del Tribunal de Luxemburgo como la contenida en la sentencia Internationale Handelsgesellschaft (17 de diciembre de 1970, causa 11/70, par. 3), donde se observa que la invocación "de los derechos fundamentales, tal como están formulados por la Constitución de un Estado miembro, o de los principios de una estructura constitucional nacional no puede afectar a la validez de un acto de la Comunidad o a su efecto en el territorio de dicho Estado", es particularmente significativa la reacción del Tribunal constitucional federal alemán.

El Tribunal de Karlsruhe, en la sentencia Solange I, de 29 de mayo de 1974, se reconoció competente -en línea teórica- para no dar aplicación en el ordenamiento nacional a los actos comunitarios en conflicto con los Derechos fundamentales contenidos en el Grundgesetz, en virtud de la ausencia total en el ordenamiento comunitario de un Parlamento democrático elegido al que estuviese confiada la función legislativa y de la inexistencia de un Bill of Rights comunitario. Con la sentencia conocida como Solange /l de 22 de octubre de 1986, el BVerfG estimó necesario suspender este control sobre las normas comunitarias en relación con los Derechos fundamentales, cuando menos mientras que el Tribunal de Luxemburgo hubiese continuado garantizando a escala comunitaria una protección suficiente a los Derechos fundamentales. Se trataba de una solución digna de ser apreciada, por la inteligente capacidad de conciliar la primacía del derecho comunitario y la permanencia de la competencia del juez constitucional, presente a pesar de todo.

Es aquí, entonces, donde hallan explicación las dudas y perplejidades que han acompañado la sentencia de 12 de octubre de 1993 sobre la ratificación del Tratado de Maastricht, en la que el Tribunal Constitucional alemán ha dado a entender que puede continuar desempeñando el papel de garante de los derechos fundamentales recogidos en la Constitución alemana, ya sea en cooperación con el Tribunal de Justicia, declarando la inaplicabilidad en Alemania de los actos comunitarios "ultra vires", es decir, carentes de fundamento en los Tratados comunitarios, o bien en conflicto con la Constitución alemana: de hecho se ha observado que, en virtud de esta argumentación, el Tribunal de Karlsruhe se ha manifestado preparado para «matar a la vaca sagrada del derecho comunitario", es decir, la regla de la aplicación uniforme de las reglas comunitarias bajo el monopolio interpretativo del Tribunal de Justicia. 
En este marco, ha despertado un gran interés la decisión con la que el Tribunal Administrativo de Frankfurt había remitido al Tribunal Constitucional la cuestión prejudicial sobre la aplicabilidad en Alemania de la regulación comunitaria del mercado de los plátanos, poniendo de manifiesto su incompatibilidad con los límites generales impuestos por la Constitución a la integración europea, con el derecho a la propiedad privada y a la libertad profesional y con el principio de no discriminación. A la vista de las notables restricciones que la disciplina comunitaria imponía, parecía ser el momento de llevar a cabo la aplicación de los contralímites. El BVerfG, con sentencia de 7 de junio de 2000, declaró inadmisible la cuestión prejudicial, poniendo de manifiesto que el Tribunal remitente había comprendido mal la precedente sentencia Maastricht y precisando ser, en línea de principio, incompetente para decidir sobre la protección de los derechos fundamentales en los actos comunitarios atendiendo a la jurisdicción del Tribunal de Luxemburgo, siempre activable mediante el mecanismo prejudicial del art. 234 TCE. Un control a escala nacional - tal y como se ha precisado- podrá ser llevado a cabo sólo para casos de violaciones continuadas y sistemáticas de los derechos en las que se dé la circunstancia de que no pueden ser remediadas a través las instancias comunitarias de tutela.

El ejemplo alemán muestra la necesidad de una garantía de los derechos fundamentales en el ámbito de la UE, como conditio sine qua non para obtener la aceptación, por parte de los Estados miembros, y sobre todo de sus Tribunales de justicia, de los principios afirmados por el Tribunal de Luxemburgo.

En ausencia de una Carta de los Derechos escrita en los Tratados Constitutivos, el Tribunal de Justicia, ejercitando de modo audaz sus poderes interpretativos, ha creado un sistema de principios fundamentales no escritos constituidos por los derechos fundamentales, tomándolos de las tradiciones constitucionales de los Estados miembros y de algunos tratados internacionales, en primer lugar el CEDH (a partir de las sentencias Stauder, en la causa 29/69 y de la ya citada Internationale Handelsgesellschaft). Esta última sentencia es particularmente significativa. En efecto, en el momento mismo en el cual el Tribunal aclara, como hemos dicho, que "el hecho de que sean minorados por un acto comunitario bien los derechos fundamentales sancionados por la Constitución de un Estado miembro, bien los principios de una Constitución nacional, no puede afectar a la validez de un acto de la Comunidad, ni a su eficacia en el territorio del mismo Estado", pero afirma también que sería otro el discurso si «hubiera sido violada una garantía análoga, inherente al derecho comunitario». Desde el momento en 
que «la tutela de los derechos fundamentales constituye parte integrante de los principios jurídicos generales cuya observancia está garantizada por el Tribunal de Justicia»; "la salvaguarda de estos derechos, informada por las tradiciones constitucionales comunes a los Estados miembros, se garantiza también en el ámbito y la estructura de la Comunidad» (Pizzorusso 2002).

Se sigue como consecuencia de esta jurisprudencia que, aunque la Comunidad no se haya adherido al CEDH, las disposiciones que lo violen no se admiten, y están destinadas a ser anuladas por el Tribunal de Justicia. En efecto, los actos normativos o administrativos comunitarios que entren en conflicto con los derechos fundamentales así reconstruidos podían censurarse por parte del Tribunal de Justicia, en el normal desenvolvimiento de sus competencias.

Además, a través del uso de las "tradiciones constitucionales comunes" como principios generales del derecho comunitario, el Tribunal contribuye a reducir las ocasiones de fricción con los Estados miembros. Es significativa a este respecto la sentencia Nold (14 de mayo de 1974) donde se afirma que "los derechos fundamentales forman parte de los principios generales del derecho, cuya observancia se garantiza por el Tribunal de Justicia. Éste, garantizando la tutela de estos derechos, debe inspirarse en las tradiciones constitucionales comunes de los Estados miembros y no podría por tanto admitir procedimientos incompatibles con los derechos reconocidos y garantizados por las constituciones de tales Estados".

Con los años, por medio de la técnica de la «incorporación» (término tomado de la historia del federalismo americano, para denominar el proceso según el cual el Bill of Rights, inicialmente considerado como aplicable sólo a los actos de la federación, fue extendido, a través de la enmienda XIV, también a los de los Estados miembros), el Tribunal ha ampliado el campo de aplicación de este control a algunas categorías limitadas de actos de los Estados miembros, en los sectores en los que éstos actúan como brazo ejecutivo de la Comunidad.

Se ha venido, por tanto, a crear en vía jurisprudencial un sistema de tutela de los derechos con relación a los actos comunitarios, sistema que ha asumido como parámetro las tradiciones constitucionales comunes y el CEDH. En otras palabras, en el ámbito de la UE se han integrado, a través de una vía basada en la ampliación y no en el conflicto, por medio de decisiones jurisprudenciales, la tutela de los derechos ofrecida por el CEDH y por las Constituciones nacionales, con resultados que pueden ser considerados globalmente satisfactorios para la garantía de los derechos. 
La cuestión de la tutela en el ámbito comunitario de los derechos fundamentales evidencia un fenómeno característico de la integración comunitaria: el desfase entre el momento decisional-político-institucional por un lado y el momento normativo-jurisdiccional por el otro, acertadamente subrayado por la doctrina (Cartabia-Weiler 2000). do.

La debilidad del primero contribuye a resaltar la fuerza del segun-

Es más, debido a múltiples aspectos la fuerza normativo-jurisdiccional de la integración europea es explicable precisamente a la luz de la debilidad del proceso político: principios potentísimos en el plano normativo como la supremacía, los efectos directos, la expansión de las competencias, la responsabilidad de los Estados, además de otros, introducidos por vía jurisprudencial, son todos explicables a la luz del principio de unanimidad que domina el proceso de toma de decisiones del Consejo, impidiendo la asunción de muchas decisiones importantes; principios que indudablemente denotan una debilidad política de los procedimientos decisionales de la Unión y que encuentra explicación también en el campo de los derechos fundamentales.

El temor a la redacción de un catálogo de derechos ha sido por largo tiempo difícil de superar, y las instituciones europeas no consiguieron llegar más allá de la Declaración conjunta del 5 de abril de 1977 , en la cual se comprometen a respetar los derechos fundamentales que resultan de las tradiciones constitucionales comunes y del CEDH (Pinelli 2003).

\section{EL MOMENTO DE LA ESCRITURA: DE LA CARTA DE NIZA A LA CONSTITUCIÓN EUROPEA}

¿Por qué, por tanto, es necesario en este punto preguntarse, si la construcción jurisprudencial llevada a cabo por el Tribunal de Justicia con prudencia y paciencia se consideraba en general satisfactoria, se ha puesto sin embargo en marcha, en un determinado punto de la evolución comunitaria, un proceso de escritura? En otros términos, si la constatación escrita de una Carta de los derechos no está justificada, como frecuentemente sucede tanto en el ámbito nacional como internacional, por la necesidad de poner remedio a una situación de generalizada violación de los derechos fundamentales, si no representa una discontinuidad respecto a una situación precedente (a diferencia de cuanto se puede decir del CEDH o de muchas Constituciones nacionales), ¿cuál es la razón? 
$Y$, en segundo lugar, ¿cuáles son las consecuencias, para el ordenamiento comunitario, de la redacción escrita de las normas sobre los derechos fundamentales?

Para responder al primer interrogante, es necesario recordar brevemente las etapas a través de las cuales se ha desarrollado el proceso de positivización.

Una primera etapa se puso en marcha por los Tratados de Maastricht y de Amsterdam. En particular, el art. 6 del Tratado sobre la Unión Europea establece que "La Unión se fundamenta en los principios de libertad, democracia, respeto de los derechos del hombre y de las libertades fundamentales, y del Estado de derecho, principios que son comunes a los Estados miembros. La Unión respeta la identidad nacional de sus Estados miembros, cuyos sistemas de gobierno se basan en los principios democráticos" (apartado 1). En el apartado 2 se afirma, después, el respeto de los derechos fundamentales, que están garantizados por el CEDH y uque resultan de las tradiciones constitucionales comunes de los Estados miembros". En el art. 7 se establece un procedimiento articulado para sancionar a los Estados miembros que hayan violado o amenacen violar los principios del art. 6. Con tal norma, por tanto, las "tradiciones constitucionales comunes" de origen jurisprudencial vienen positivizadas en el Tratado.

Más adelante se inserta en el Tratado CE la noción de ciudadanía de la Unión europea. Tal noción no sustituye a la nacional, sino que viene a añadir, en beneficio de los ciudadanos de los Estados miembros, un cierto número de derechos, creando al mismo tiempo un sentimiento de pertenencia común. En ese ámbito, los ciudadanos de la Unión ven reconocidos el derecho de circular y establecerse libremente sobre el territorio de los Estados miembros y el de votar y ser elegidos en las elecciones municipales de los Estados miembros en los cuales cada ciudadano reside, el derecho de beneficiarse de la protección diplomática o consular por parte de las autoridades de cualquier Estado europeo.

Todas son disposiciones (los arts. 6 y 7 del Tratado sobre la Unión, y las normas sobre la ciudadanía de la Unión contenidas en los arts. 17 y ss. del Tratado CE) que volvemos a encontrar, como ya se ha dicho al comienzo, en la Constitución europea.

Se ha puesto de relieve (Gambino 2005) que, en este punto de la evolución comunitaria, un catálogo de derechos fundamentales comunitarios parecía necesario con el fin de reconocer un papel más central a las instituciones representativas de la Unión europea, también para 
superare la (reiterada) crítica de déficit (democrático y) constitucional de las instituciones comunitarias globalmente consideradas.

Tal necesidad era evidente sobre todo después de que, con el Tratado de Amsterdam (que entró en vigor, recuérdese, en mayo de 1999) se había establecido la creación de un espacio de libertad, seguridad y justicia: la Unión europea perdía así su naturaleza económica y monetaria, y surgía la exigencia de que las nuevas actividades de la Unión fueran presididas por una clara protección de los derechos fundamentales, idónea para orientar la actividad del legislador (Paciotti 2001).

En la Conferencia intergubernamental de Colonia, de 1999, se intenta dar solución a tales problemas iniciando un proceso que debería llevar, con el Tratado de Niza, a hacerse cargo de un catálogo de los Derechos y de las Libertades fundamentales que debería asumirse como Bill of rights de un constitucionalismo europeo más maduro, aunque fuese siguiendo el camino de la ulterior integración de los tratados y no por la vía del recurso a procesos constituyentes. Algunos autores (Manzella 2001) han subrayado la coincidencia de tiempos entre el Consejo de Colonia (3-4 junio 1999) y la última guerra de los Balcanes (26 marzo-10 junio 1999): en el momento en el cual se implica en una "guerra por los derechos", difícil de explicar a una opinión pública acostumbrada a una imagen "mercantil» de la UE, se advierte de manera todavía más fuerte la necesidad de explicitar, de hacer visible, el fundamento profundo de la UE. De este modo se explicarían las palabras "fuertes" de la declaración de Colonia: para los Jefes de Estado y de Gobierno, "la tutela de los derechos fundamentales constituye un principio fundador de la UE", y no sólo eso, "el presupuesto indispensable de su legitimidad".

Estrictamente ligado a tal explicación está el tema de la ampliación: en el momento en el cual Europa se abre a muchos nuevos miembros, que provienen en gran parte de precedentes experiencias autoritarias y de diversas tradiciones jurídicas, debe estar bien clara su compleja identidad: y, en primer lugar, el catálogo de los derechos, que no puede dejarse por más tiempo al albur de complejos, y difícilmente cognoscibles, precedentes judiciales.

Además, no debe olvidarse una tendencia a la codificación de los derechos que existe en muchos ordenamientos nacionales, también en aquéllos en los que de modo previo habían sido garantizados perfectamente en vía jurisprudencial: piénsese en las experiencias de Nueva Zelanda, Canadá, Reino Unido. El respeto de los derechos fundamentales es hoy una fuente imprescindible de legitimación del poder: hasta el punto de que se considera necesaria su explicitación también en 
Estados ya democráticos, en los cuales los derechos se hallaban garantizados, con independencia de su positivización.

El Parlamento europeo, el Consejo y la Comisión adoptaban solemnemente (Tratado de Niza) la Carta de los Derechos fundamentales (8 de diciembre de 2000); se trataba de una 'declaración política' todavía no dotada de valor jurídico vinculante.

Sin embargo, como se ha dicho (Celotto-Pistorio 2004), la «vitalidad" de la Carta, no ha esperado los tiempos de las decisiones políticas: así, se ha desarrollado un amplio debate acerca de su "fuerza", según dos itinerarios diferentes. El relativo a su fuerza política se ha resuelto rápidamente en clave de obligatoriedad, habiendo tenido puntualmente las instituciones europeas la convicción de estar obligadas a respetar la Carta en el proceso de toma de decisiones, hasta el punto de que la Comisión, por ejemplo, ha instituido los correspondientes procedimientos internos en orden a activar un control preventivo de conformidad a los derechos formalizados en ella.

El debate relativo a la fuerza jurídica de la Carta, sin embargo, parece más complejo y laborioso, conviniendo en general sobre el hecho de que la Carta sería un instrumento de soft law, cuya utilidad afectaría sobre todo a fines interpretativos. Sin embargo, no se ha acabado aquí el debate, sobre todo por el impulso de algunos jueces, comunitarios y nacionales, que se han referido con frecuencia $-y$, a veces, aplicadola Carta. Incluso antes de su proclamación oficial, por ejemplo, el Tribunal Constitucional español, con la STC 292/2000, de 30 de noviembre, (en el Fundamento Jurídico 8) ha hecho referencia al art. 8, con el fin de reforzar la declaración de ilegitimidad de diversos artículos de la ley $15 / 1999$, en la parte en la que se preveía, sin las garantías adecuadas, el intercambio de los datos personales entre diversas administraciones. Estas posiciones se han visto apoyadas por parte de la doctrina, que ha intentado encontrar un fundamento a la inmediata obligatoriedad de la Carta, aproximándola a las decisiones del art. 249 TCE; considerándola vinculante, cuando menos, para las Instituciones que solemnemente la han adoptado, o también para el Tribunal, mediante la aplicación del art. 6 TUE; leyéndola como un acto de naturaleza constituyente, sustancialmente constitucional, o simplemente como fuente atípica, es decir directamente productiva; o, incluso, como base para la formación de una costumbre europea en materia de derechos fundamentales.

Es en la Declaración de Laeken sobre el futuro de la Unión (15 de diciembre de 2001) en la que aparece, por primera vez de manera explícita, el término Constitución, y se plantea la cuestión de si la 'Carta' debía ser integrada en los Tratados básicos, y si la Unión debía adherirse 
al CEDH, en pocas palabras, si el mismo proceso de reforma de los tratados no debía llevar a la adopción de un texto constitucional. La idea de crear una Convención nacía, desde esta perspectiva, para responder a algunos interrogantes fundamentales sobre el futuro de la Unión. Las conclusiones de los trabajos de la misma deberían constituir la base para las futuras discusiones de la $\mathrm{CIG}$, la única legitimada para adoptar las decisiones finales.

Come es conocido, no han faltado los que se han opuesto a semejante proyecto de codificación de los derechos fundamentales y, más en general, de elaboración de un texto escrito de Constitución europea. El más célebre "enemigo" de este proceso es el académico estadounidense, pero ampliamente radicado en Europa, Joseph Weiler, autor de un célebre volumen sobre la Constitución europea. En los pasados decenios él ha sido uno de los principales sustentadores de la construcción jurisprudencial. Weiler parte de la constatación de que existe una arquitectura constitucional en la Unión europea independientemente de la adopción de una Carta constitucional formal. Como sucede en otros ordenamientos, especialmente del mundo anglosajón, la Constitución europea no está escrita, pero de ninguna manera esta característica entorpece su eficacia. Es más, si se consideran las características de la integración europea, la forma no escrita es la que se encuentra más en consonancia con el ordenamiento constitucional de la UE: el principio de tolerancia constitucional, que constituye el arquitrabe de la inédita arquitectura constitucional de Europa, se nutre mejor en un ambiente de constitución no escrita. Por medio del principio de tolerancia constitucional los pueblos europeos aceptan - dando prueba así de una notable tolerancia cívica- estar vinculados por un pueblo que no es "mi" pueblo, sino un pueblo de "otros". La puesta por escrito de un texto constitucional podría atrofiar, teóricamente, el original principio de tolerancia constitucional del cual trae fundamento la Unión europea y que refleja toda la especificidad (Weiler 2003 (1), 511 y ss.) del ordenamiento comunitario, un ordenamiento que bajo múltiples perfiles ha puesto en crisis los confines entre las categorías tradicionales del derecho público, como son los que hay entre Estado y organización internacional; entre ciudadanos y extranjeros; entre constitución en sentido clásico y Tratado internacional, y así sucesivamente.

Por lo que se refiere específicamente a la Carta de los derechos, el mismo autor se ha expresado en términos clara y decididamente negativos sobre la hipótesis de un texto escrito: "redactando un elenco y, un día, quizá, incorporándolo al ordenamiento jurídico, nosotros habremos sacrificado, al menos en parte, una de las características verdaderamente originales de la arquitectura constitucional pre-Carta en el 
campo de los derechos humanos - la capacidad de usar el sistema legal de cada Estado miembro como un laboratorio orgánico y viviente en la protección de los derechos humanos que después, caso por caso, pueden ser adaptados y adoptados para las necesidades de la Unión por parte del Tribunal europeo, en diálogo con sus contrapartes nacionales. La Carta podrá no impedir esto proceso, pero lleva consigo el riesgo de inducir a una jurisprudencia más replegada sobre sí misma y de congelar el diálogo constitucional» (Weiler 2003 (2), 528).

Para dar una respuesta más completa al primer interrogante (¿por qué "escribir» los derechos?) es necesario quizá tomar en consideración el segundo: ¿qué cosa cambia, escribiendo los derechos dentro de un texto normativo que se sitúa en posición de supremacía sobre las fuentes del derecho de la UE?

Me parece que se deben poner de relieve al menos tres consecuencias.

a) Visibilidad (Ziller 2004): la Carta hace más fácilmente «cognoscibles" los derechos fundamentales. El mismo Consejo europeo de CoIonia había afirmado la necesidad de "elaborar una Carta de los derechos con el fin de sancionar de modo visible la importancia capital y el alcance para los ciudadanos de la Unión" (Pinelli 2003). Esto comporta consecuencias relevantes. Antes que nada, para los ciudadanos europeos singulares. Éstos adquieren la conciencia de los propios derechos, en cuanto se trata de situaciones jurídicas accionables. Además la Carta, parte integrante de la Constitución, será leída por docentes, periodistas, militantes de asociaciones: contribuirá a la creación progresiva de una cultura común de ciudadanía de la Unión. Existen consecuencias para el mismo derecho de la Unión: el hecho de que numerosos abogados y jueces poco expertos en el derecho europeo puedan referirse a un texto mucho más fácilmente accesible que las recopilaciones de sentencias o las revistas jurídicas europeas, se traducirá de por sí en una mayor efectividad del derecho europeo de los derechos fundamentales.

b) Carácter promocional de los derechos (Gambino 2005): a la función previamente vigente de mero límite a la adopción de actos comunitarios en violación de derechos se acompaña, ahora, una de tipo positivo, la de constituir un espacio común de libertad, seguridad y justicia, capaz de guiar el propio ejercicio, por parte de las instituciones comunitarias, de sus competencias reconocidas. Así, los derechos han desarrollado hasta aquí una función instrumental, en razón de las exigencias vinculadas a los avances en la construcción del mercado común europeo, su inserción dentro de la Constitución desvela una nue- 
va vocación, capaz de asegurar mayor claridad y brillo a conceptos igualmente centrales en el proceso de construcción europea, como la ciudadanía de la Unión o el significado de la recíproca confianza entre los Estados en un espacio común de libertad, de seguridad y de justicia. Los derechos fundamentales, por tanto, ya no constituyen un mero límite, impuesto a la acción de las instituciones comunitarias o de los Estados miembros en el campo de aplicación del derecho de la Unión. A la obligación previamente existente (de no violar los derechos fundamentales) impuesta a las instituciones y a los órganos de la Unión, como también a los Estados miembros en sede de actuación del derecho comunitario, se sigue ahora una de tipo promocional, aquélla según la cual "los citados sujetos respetan los derechos, observan los principios y promueven su aplicación según las respectivas competencias" (art. 51.1 de la Carta, ahora art. II-111.1 TC).

c) Mutación de las relaciones entre instituciones políticas y jurisdiccionales de la Unión: en una primera impresión, es fácil sostener (Grimm 2004) que la puesta por escrito de una Carta de los derechos fundamentales determina una reducción del "poder de los jueces", que se encuentran limitados por un texto escrito que deben interpretar. Por lo demás, otros autores (Cartabia 2004) han puesto de relieve que el papel de los jueces, ya sea del Tribunal de Justicia o de los jueces nacionales, podría resultar exaltado por la elaboración de un texto escrito de un catálogo constitucional de derechos. Las razones aducidas son varias. Ante todo, la Constitución europea no elimina las otras fuentes del Derecho constitucional europeo no escrito, como son las tradiciones constitucionales comunes, o las convenciones internacionales; además, el texto contiene principios y enunciados que no sofocan la libertad interpretativa de los jueces; el Tribunal de Justicia exaltará su papel de Tribunal constitucional y, por tanto, legitimado por la misión de "guardián de la Constitución europea», no verá perjudicadas sus propias potencialidades, sino que acrecentará su autoridad; sobre el ámbito nacional la puesta por escrito de la Constitución europea puede legitimar el desarrollo creativo de la actividad jurisdiccional, permitiendo aplicar también a las normas constitucionales las propiedades de supremacía, efecto directo e indirecto típicas del derecho comunitario, que difícilmente podían referirse a los principios constitucionales no escritos elaborados por el Tribunal de Justicia. En cuanto que los derechos fundamentales han sido tutelados por el Tribunal de Justicia en calidad de principios no escritos derivados de las tradiciones constitucionales comunes a los Estados miembros y del CEDH, ningún juez nacional pensaba hacer un uso interno, en los ordenamientos nacionales, de los criterios propios del común derecho europeo. Por el contrario, su 
concreción escrita expondrá a los jueces nacionales a la tentación de atender también a la fuente constitucional europea para resolver los casos internos a la luz de sus principios y de sus derechos, como si tuviesen las características de la directa aplicabilidad. Por medio del efecto directo e indirecto y de la supremacía del derecho comunitario, los principios constitucionales y sobre todo los derechos constitucionales europeos acabarán por ser directamente aplicados por los jueces - seguro que más allá de los límites del campo de aplicación rigurosamente trazado por el art. II-111 de la Constitución europea.

\section{ALGUNAS CARACTERÍSTICAS DEL BILL OF RIGHTS EUROPEO}

La Carta de los derechos de la Unión europea, que hasta aquí se ha intentado ilustrar en relación con sus raíces en la evolución del ordenamiento de la UE, puede ser también analizada desde otro punto de vista: el del derecho comparado. A tal fin, la comparación más útil no es la que pueda hacerse con otras Cartas o declaraciones supranacionales, sino con las declaraciones de los derechos contenidas en las constituciones nacionales. Y ello porque, no obstante la indudable influencia ejercida ya por los Tratados comunitarios, ya por el CEDH (cuyas disposiciones la primera convención estaba llamada a racionalizar, sobre la base del mandato recibido en Colonia), sin embargo, la Convención, por su misma composición, ha operado en modo más similar a una asamblea llamada a escribir un texto constitucional que a una conferencia intergubernamental de la que se reclama la redacción de un Tratado internacional.

Desde este punto de vista, podemos decir que la codificación de los derechos en la Constitución europea presenta algunas de las características propias de la más reciente fase del constitucionalismo.

Ante todo, se trata de un texto precedido de un preámbulo. La peculiaridad, en el caso de la Carta de los derechos, es que con su incorporación a la Constitución, el preámbulo se encuentra al inicio de la Carta, pero no al inicio de la Constitución, que tiene su propio preámbulo. Otra peculiaridad es que el preámbulo señala (ésta es una modificación respecto a la Carta de Niza) la necesidad de interpretar la Carta "debiendo tener en cuenta" las explicaciones elaboradas por el Presidium de la Convención que la elaboró y actualizadas por el Presidium de la Convención que ha escrito la Constitución, cuyo texto forma parte de una Declaración anexa a la Constitución. Por tanto, la voluntad de los Founders está presente de manera mucho más viva y cercana de cuanto sucede habitualmente con las Constituciones na- 
cionales, en las cuales no nos parece haber encontrado disposiciones de este tipo.

En segundo lugar, se trata de un catálogo "largo", que aproxima la Carta a las constituciones más recientes, diferenciándola no sólo de las del siglo XIX, sino también de las aprobadas en la mitad del siglo XX, como la italiana o la alemana. Los derechos tutelados, en efecto, no son sólo los civiles y sociales, sino también los de la denominada "tercera generación", como el derecho a la protección de los datos personales (art. II-68), el de los menores a "expresar libremente la propia opinión» (art. II-84), los derechos de las personas discapacitadas (art. II-86), el derecho de acceder a un servicio de colocación gratuito (art. II-89); la protección del consumidor (art. II-98); el acceso a los servicios de interés económico general (art. II-96). Se dispone (art. II-63) la prohibición de las prácticas eugenésicas, de la clonación reproductiva de los seres humanos, de hacer del cuerpo humano y de sus partes una fuente de lucro. También la igualdad se lee en clave, en un doble sentido. De un lado, a través de la multiplicación (en el art. II-81) de las causas de no discriminación (que se extienden, por ejemplo, también a la discapacidad o a la orientación sexual); de otro, a través del explícito reconocimiento de la diversidad cultural, religiosa y lingüística (art. II-82). Está prevista asimismo la introducción de "acciones positivas" para lograr la paridad hombre-mujer (art. II-83).

Se asiste, en otros términos, a la codificación de un gran número de derechos fundamentales. Esto se debe, bien al impulso de las nuevas tecnologías (piénsese en la bioética) que requieren nuevas respuestas, bien a un proceso de especificación de derechos ya existentes (en el sentido indicado por Peces Barba): piénsese, por ejemplo, en el derecho, ya citado, al acceso a un servicio de colocación gratuito, habitualmente reconducido a la tutela general del "derecho al trabajo" asegurada por las constituciones.

Tal proceso parece ser fruto, en gran parte, de la técnica utilizada en la redacción de la Carta, es decir, la codificación de todos los derechos en cualquier modo reconocidos por los tratados, por el CEDH, por las Cartas sociales europeas, por la jurisprudencia.

No se asiste, sin embargo, al otro aspecto del "alargamiento" de las Cartas constitucionales que se detecta en el constitucionalismo más reciente: es decir, el carácter extremamente detallado de las disposiciones. Tal "minuciosidad", que en muchos casos asimila el texto de las constituciones al propio de las leyes, puede encontrarse tanto en las nuevas constituciones como en las modificaciones añadidas a otras, menos recientes (como la alemana o italiana). Ésta se debe esencial- 
mente al hecho de que los textos en cuestión son fruto de acuerdos entre los partidos, dominados por condicionantes ligados a los réditos políticos a corto plazo. Se abandona de tal modo el carácter principial propio de los derechos fundamentales, insertando en los artículos constitucionales prescripciones que, en realidad, encontrarían su lugar en las leyes ordinarias, si no en actos administrativos. La Convención europea, en cuanto compuesta de personalidades políticas no inmediatamente responsables frente a los electores, ha podido trabajar sin las presiones que normalmente caracterizan el sistema político, produciendo una Carta que contiene más principios que reglas detalladas, y que por este aspecto no es asimilable al constitucionalismo más reciente. Como se ha dicho, los derechos se codifican en la Carta en manera "concisa, austera y lapidaria" (Díez Picazo).

La Constitución, por lo demás, a diferencia de cuanto sucede habitualmente en las constituciones nacionales, especifica el valor de las disposiciones de principios, excluyendo expresamente el carácter autoaplicativo y la "eficacia horizontal» (en las relaciones entre particulares). En efecto, se precisa (art. II-112, apartado 5), que "las disposiciones de la presente Carta que contengan principios podrán aplicarse mediante actos legislativos y ejecutivos adoptados por las instituciones, órganos y organismos de la Unión, y por actos de los Estados miembros cuando apliquen el Derecho de la Unión, en el ejercicio de sus competencias respectivas. Sólo podrán alegarse ante un órgano jurisdiccional en lo que se refiere a la interpretación y control de la legalidad de dichos actos".

Otra característica de la Carta de los derechos es su carácter completo. A pesar de que se trata de normas dirigidas a limitar la actuación de las instituciones comunitarias, que no tienen la amplitud de poderes propios de un Estado nacional. Tal opción se explica con dos razones (Grimm): por un lado, la integración europea está destinada a progresar, afectando a ámbitos hoy desconocidos, y no tendría sentido que, a cada nuevo paso de la integración europea, fuese necesario insertar nuevos derechos; por otro, porque sólo ante la presencia de un catálogo completo de derechos puede realizarse un balance correcto. En particular, puede reducirse el predominio hasta ahora existente de los derechos de carácter económico, en nombre de los derechos culturales y sociales.

Original es también la disposición "topográfica» de los derechos en el texto. Abandonando la tradicional subdivisión en derechos civiles, políticos, sociales, se han dispuesto en torno a 6 valores, a los que se dedican los 6 Títulos: dignidad, libertad, igualdad, solidaridad, ciuda- 
danía, justicia. No existe, a diferencia de lo que ocurre en algunas constituciones nacionales, una jerarquía de los derechos fundamentales.

Una ulterior característica es la apertura al derecho internacional de Ios derechos humanos: a partir del art. I-9 se ponen las bases para la adhesión de la UE al CEDH, mientras los arts. II-112 y II-113 se preocupan de reiterar la "preferencia" por dicho convenio; además de por el derecho internacional y por las convenciones internacionales de las cuales la Unión o todos los Estados miembros forman parte (art. II-113).

También la limitación de los derechos fundamentales se produce según una técnica que puede encontrarse en las constituciones más recientes y no, por el contrario, en las de la segunda postguerra mundial. Se trata de la previsión, en el art. II-112, de una cláusula limitativa general, aplicable a todos los derechos y las libertades garantizados en la Carta. No existen, por tanto, derechos cuyo ejercicio no puede ser sometido a límites, pero las limitaciones deben producirse en el marco de principios delineado en dicha disposición.

Una cláusula de este tipo, presente ya en algunos documentos internacionales (art. 29 de la Declaración universal de los derechos del hombre de 1949; art. 26 de la Declaración de los derechos y libertades fundamentales del Parlamento europeo de 1989), había sido asumida como propia por algunas recientes constituciones, partiendo de la Carta canadiense de derechos y de libertades de 1982, hasta llegar al Bill of Rights de Nueva Zelanda de 1991, a las leyes fundamentales de Israel de 1992, a la Constitución sudafricana de 1996. Esto tipo de cláusulas permite un mayor espacio a los jueces del que dejaban las cláusulas limitativas puntuales contenidas, por ejemplo, en la Constitución italiana o en la alemana (De Siervo).

Con base en el art. II-112, las limitaciones al ejercicio de los derechos garantizados deben: a) estar previstas por la ley; b) respetar el contenido esencial de los derechos; c) respetar el principio de proporcionalidad; d) ser necesarias y consecuentes con los fines interés general reconocidos por la Unión o a la exigencia de proteger los derechos y las libertades de los demás.

a) En primer lugar, para que la limitación del ejercicio de un derecho no entre en contradicción con la Carta, debe estar prevista por la "ley". Después de algunas dudas, testimoniadas en los trabajos preparatorios, el texto final de la Carta acoge la referencia a la "ley», presente, además de en las constituciones nacionales, en algunos documentos internacionales, como la Declaración de los derechos del 
hombre de la ONU o el propio CEDH (arts. 8, 9, 10 y 11). En el momento de la introducción del término "ley" se ha afirmado que tal palabra debe ser entendida, según la interpretación ofrecida por el TEDH, como ley en sentido material y no formal. Estarían comprendidas, por tanto, en la noción, y podrían intervenir legítimamente para regular el ejercicio del derecho, normas infralegislativas y, en los países del common law, también consuetudinarias y jurisprudenciales, dentro de los límites establecidos por el Tribunal europeo, para el que la "ley" debe "ser accesible al cada individuo" y debe "prever las consecuencias de su comportamiento" (vid. TEDH, 26 de abril de 1979, Sunday Times c. Regno Unito, serie A, 30; 24 de abril de 1990, Huvig c. Francia, serie A 176-B). Algún cambio sobre esta situación podría derivar de la existencia en la Constitución de una verdadera y propia "ley europea», acto del poder legislativo, distinta del reglamento, acto del ejecutivo (art. I-33).

b) El respeto del contenido esencial del derecho constituye un tope para las leyes que pretendan limitar el ejercicio de los derechos y de las libertades garantizados por la Carta: no podrán nunca adentrarse tanto que lleguen a afectar al contenido esencial. Se trata de un límite que, presente en algunos de los documentos internacionales aludidos (art. 26 de la Declaración del Parlamento europeo) y en la jurisprudencia del Tribunal de Justicia, ha sido asumido como propio por muchas constituciones nacionales. Además de la ya citada constitución sudafricana, piénsese, por permanecer entre los países de la Unión europea, en la alemana (art. 19, apartado 2), española (art. 53), portuguesa (art.18, apartado 3). Por lo demás, la noción surge en vía jurisprudencial también en otros ordenamientos, entre los cuales está el italiano (vid. p. ej. Corte costituzionale 7 de febrero de 2000, n. 42). La inserción en el texto de la Carta de la referencia al "contenido esencial» obligará a la jurisprudencia comunitaria a enfrentarse con tal noción: ésta, en efecto, viene a constituir, como la doctrina alemana y la española ya han puesto ampliamente en evidencia, el "límite de los límites", que marca la frontera más allá de la cual cualquier actividad limitativa de los derechos garantizados es contraria a la Carta. Una misión nada simple, tratándose de un concepto jurídico indeterminado, que debe ser circunscrito y especificado en vía interpretativa.

c) La expresa referencia al "principio de proporcionalidad" constituye la codificación del criterio fundamental de ponderación de derechos introducido en vía jurisprudencial en casi todos los ordenamientos, por parte de los jueces constitucionales, y ya bien fundamentado en la jurisprudencia del Tribunal de Justicia (p. ej. CGCE 30 de julio de 1996, Bosphorus c. Ministerio de los Transportes, Energía y Telecomunicaciones, C-84/95, en Rec. I-3953). 
d) La afirmación según la cual las limitaciones deben ser necesarias y deben responder a las finalidades del interés general reconocidas por la Unión o a la exigencia de proteger los derechos y las libertades de los demás contribuye a diferenciar la cláusula limitativa de la Carta de las contenidas tanto en los documentos internacionales como en las constituciones que prevén una cláusula limitativa general. Falta, en efecto, en el art. II-112, la referencia a una "sociedad democrática", presente no sólo en los textos mencionados, sino también en las cláusulas limitativas relativas a específicos derechos del CEDH, y que comparecía en todos los documentos tomados como base por el Presidium en el curso de los trabajos preparatorios. La versión final del artículo parece recibir de nuevo, de manera más acentuada que las precedentes, la influencia de la jurisprudencia comunitaria en materia de limitación de los derechos, como evidencian también las notas del Presidium.

El Tribunal de Justicia ha afirmado repetidamente que "pueden aportarse restricciones al ejercicio de los derechos fundamentales, en el marco de una organización de mercado común, a condición de que correspondan efectivamente a objetivos de interés general perseguidos por la Comunidad y no constituyan, en relación a la finalidad perseguida, una intervención desmesurada e intolerable, de modo que ponga en duda la esencia misma de estos derechos" (p. ej. CGCE, 12 de julio de 1989, Schräder, C-265/87, en Rec. 2237; 8 de abril de 1992, Commissione c. Germania, C-62/90, en Rec. I-2575; 30 de julio de 1996, Bosphorus c. Ministerio de los Transportes, Energía y Telecomunicaciones, cit.; 13 de abril de 2000, C-292/97, Karlsson y a.).

A diferencia de cuanto sucede en las Constituciones más recientes, la Carta no prevé la posibilidad de derogar, para estados de emergencia o de necesidad, la disciplina de los derechos garantizados. En esto se distingue también del CEDH, cuyo art. 15 concede a los Estados el derecho de derogación, "en caso de guerra o en caso de otro peligro público que amenace la vida de la nación", con la excepción de algunos derechos, considerados no derogables, dictando después las condiciones e instituyendo controles sobre el uso del instrumento: en ausencia de una disposición semejante resta abierto el interrogante sobre los instrumentos de "emergencia" disponibles en el ámbito de la Carta (más allá de lo establecido por el art.Il-114, sobre el abuso del derecho). Tampoco prevé cláusulas derogatorias generales (o de flexibilización), que permitan al poder político derogar las previsiones de la Carta, sustrayendo al control judicial las propias decisiones, sobre el modelo de la contenida en el art. 33 de la Carta canadiense de los derechos y de las libertades (notwithstanding clause). 
Una cuestión que se puede en este punto plantear, por concluir este rápido examen de la Carta de Derechos, se refiere a su guardián. La solución parece simple: son los jueces nacionales, en lo que afecta al control de los actos nacionales que entren en conflicto con ella, el Tribunal de Justicia para el control de los actos de la UE.

Aquí, sin embargo, se abre un interrogante posterior: ¿es el Tribunal de Justicia un garante satisfactorio, en cuanto a composición, método de trabajo, vías de acceso?

En particular, las actuales vías de recurso parecen capaces de provocar un déficit de tutela en relación con los actos comunitarios, es decir, precisamente los actos respecto a los cuales la Carta ha sido pensada, sobre todo a consecuencia de la interpretación restrictiva dada por el Tribunal de Justicia al art. 230, apartado 4, del Tratado CEE (sobre la base de la sentencia Plaumann: 15 de julio de 1963, caso 25/1962). En la cumbre de Colonia se había hipotizado sobre la posibilidad de introducir un recurso directo, similar al alemán y español, pero después tal hipótesis se descartó. Posteriormente, en el momento de escribir la Constitución, se decidió no entrar a reformar el Tribunal de Justicia, a pesar de que se creó por parte del Presidium de la Convención un "círculo de discusión" orientado precisamente a la reformulación del art. 230, apartado 4, del TCE, que sin embargo produjo resultados limitados (la nueva redacción del art. III-365, apartado 4, hace más accesible la impugnación de los actos reglamentarios, requiriéndose que afecten al recurrente directamente, y no individualmente) (sobre el tema, A. Rallo Lombarte 2004). El riesgo, por tanto, es que la Carta quede como una mera declaración política, donde se afirma la exigencia de someter los cada vez más numerosos actos comunitarios al respeto de los derechos fundamentales, carente sin embargo de efecto jurídico inmediato.

\section{LA CARTA DE LOS DERECHOS Y LA RELACIÓN UE-ESTADOS MIEMBROS Y UE-CEDH}

La codificación de los derechos en la Constitución europea es parte de un proceso que parece imparable: el de la proliferación de los catálogos de los derechos. Esta proliferación, como se ha puesto acertadamente de relieve, provoca frecuentemente más problemas que ventajas, hasta el punto de preguntarse si un aumento de las normas no produce más bien un debilitamiento de la protección (Romboli 2003). En particular, la multiplicación de los catálogos puede minar la certeza del derecho y acrecentar la probabilidad de conflictos entre tribunales. Piénsese que, en cualquier país europeo, uno se encuentra realmente 
frente a seis niveles judiciales: jueces de primera instancia, apelación, Tribunal supremo, Tribunal constitucional nacional, Tribunal europeo de los derechos del hombre (Estrasburgo), Tribunal de Justicia de la Unión europea (Favoreu 2004).

La Constitución, como (y todavía en mayor medida) la Carta de los derechos que incorpora, refleja la conciencia de esta situación, e intenta introducir una serie de mecanismos dirigidos a hacer menos probables los conflictos entre tribunales protectores de los derechos que actúan en Europa. Es, en efecto, en el Título VII de la Parte II de la Constitución (Disposiciones que regulan la interpretación y la aplicación de la Carta) donde se encuentran las mayores novedades respecto al texto de la Carta de Niza.

Tales disposiciones muestran la cautela con la que se han movido los autores de la Carta, primero, y los de la Constitución, después. Se ha pretendido evitar cualquier sospecha de querer utilizar la codificación de los derechos fundamentales para obtener una no debida ampliación de las competencias de la Unión y una disminución de las identidades constitucionales de los Estados singulares.

Explícito, en este sentido, es el art. II-111, sobre el ámbito de aplicación de la Carta (que reproduce, pero acentuando las cautelas, el art. 51 de la Carta de Niza). Se establece que "las disposiciones de la presente Carta están dirigidas a las instituciones, órganos y organismos de la Unión, dentro del respeto del principio de subsidiariedad, así como a los Estados miembros únicamente cuando apliquen el Derecho de la Unión. Por consiguiente, éstos respetarán los derechos, observarán los principios y promoverán su aplicación, con arreglo a sus respectivas competencias y dentro de los límites de las competencias que se atribuyen a la Unión en las demás Partes de la Constitución. 2. La presente Carta no amplía el ámbito de aplicación del Derecho de la Unión más allá de las competencias de la Unión, ni crea ninguna competencia o misión nuevas para la Unión, ni modifica las competencias y misiones definidas en las demás Partes de la Constitución".

Sin embargo, la experiencia de los Estados federales nos muestra cómo el sobrevenir de una Carta de los derechos opera, habitualmente, en sentido centrípeto, acrecentando las competencias de la Federación. Esto ha ocurrido tanto en Estados Unidos, donde la eficacia de las primeras diez enmiendas se ha extendido a los Estados (como consecuencia de un acontecimiento de la importancia de la guerra civil), como en Canadá, donde los temores manifestados por las Provincias en el momento de la inserción en la Constitución de la Canadian Charter of Rights parecen confirmados plenamente por la jurisprudencia de 
la Corte suprema: así como deseaba su principal sostenedor, el primer ministro Pierre Trudeau, la Carta ha operado, efectivamente, como instrumento para la construcción de una «identidad canadiense».

Un hito decisivo en las relaciones entre la UE y los Estados miembros, en materia de derechos, es el art. Il-113, según el cual "Ninguna de las disposiciones de la presente Carta podrá interpretarse como limitativa o lesiva de los derechos humanos y libertades fundamentales reconocidos, en su respectivo ámbito de aplicación, por el Derecho de la Unión, el Derecho internacional y los convenios internacionales de los que son parte la Unión, la Comunidad o los Estados miembros, y en particular el Convenio Europeo para la Protección de los Derechos Humanos y de las Libertades Fundamentales, así como por las constituciones de los Estados miembros".

Esta previsión, garantizando los mayores niveles de protección de los derechos previstos (también) por las Constituciones de los Estados miembros, es una disposición crucial para el futuro de las relaciones UE-Estados. Ella, en efecto, podrá conllevar que los Tribunales constitucionales $-\mathrm{y}$, en último término, cada uno de los jueces para las disposiciones que tengan eficacia directa-, allí donde se manifieste un mayor nivel de protección en la Constitución nacional, apliquen la norma de esta última, inaplicando en cambio la norma comunitaria, en una aplicación pro individuo del standard de tutela comunitario o nacional de que se trate. En la práctica, el art. II-113 - que corresponde al antiguo art. 53 de la Carta- se configura como una cláusula que mitiga el principio del art. I-6, de la primacía del derecho de la Unión, y justifica las limitaciones que a esta primacía ponga el derecho constitucional nacional. Todo esto se hace aún más real si se considera el contenido del art. I-5 del Tratado constitucional que proclama el respeto a la identidad nacional y a las estructuras políticas y constitucionales de los Estados miembros. Se considera que dicha proclamación no sólo va aparejada al reconocimiento de la primauté, sino que -además- se antepone a ésta. La lectura sistemática del art. I-5 y I-6 comporta, en consecuencia, no sólo que los principios de orden constitucional fundamental de los Estados acompañan a la primauté, sino que se anteponen a la misma.

Entonces, por un lado, el art. II-113 del Tratado permite una operatividad dinámica de las limitaciones nacionales a la primauté, sobre la vertiente de la tutela de los derechos inviolables del hombre, en garantía del nivel más alto de protección (prescindiendo del hecho de que derive de fuente comunitaria o nacional); por otro, el art. I-5 admite que los principios supremos del ordenamiento estatal, en cuanto formas esenciales de la identidad nacional, preceden a la misma primauté, 
según lo han puesto de manifiesto el Tribunal constitucional español en la Declaración 1/2004 de 13 de diciembre de 2004 y el Conseil constitutionnel francés en la Decisión n. 2004-505, ambas sobre la compatibilidad de la Constitución europea con las constituciones nacionales. Especialmente el Conseil constitutionnel establece una relacción entre el art. III-112 y el art. I-5: entre los los fines de interés general reconocidos por la Unión que permiten limitar los derechos fundamentales el Conseil coloca también los del art.I-5, cuando dice che la Unión respeta "las funciones esenciales del Estado, especialmente las que tienen objeto garantizar su integridad territorial, mantener el orden público y salvaguardar la seguridad nacional».

En la práctica, la UE — una vez que ha llegado al momento de la emanación de su propia Constitución formal-, de un lado asegura que los derechos del hombre sean tutelados al nivel más elevado posible, aun en detrimento de la primauté del derecho europeo, concibiendo una "garantía de mínimos, sobre los cuales puede desarrollarse el contenido de cada derecho y libertad, hasta alcanzar la densidad de contenido asegurada en cada caso po el Derecho interno" (v. la Declaración 1/2004, cit.); de otro excluye que el derecho europeo pueda interferir con las estructuras políticas fundamentales de los Estados.

En el momento en que la UE amplía su propio horizonte finalístico, en cuanto auténtico Estado de base federal, y admite positivamente la primauté de su propio derecho sobre los derechos nacionales, ella no puede dejar de consentir —síntoma de la Unión de las diversidades (como no por casualidad reza el lema de la Unión, ex art. I-8) - el respeto a las identidades nacionales y a la tutela (dinámica) de los derechos humanos (Celotto-Groppi 2004).

Análogo discurso puede hacerse con relación al CEDH: la gran novedad está aquí representada por el art.I-9, que abre la vía a la adhesión de la UE al CEDH, con todo lo que se conseguirá en términos de necesario respeto, por parte de todos los órganos de la Unión, comprendido el Tribunal de Justicia, de la jurisprudencia del Tribunal de Estrasburgo (el protocolo XIV del CEDH, firmado el 13 de mayo de 2004, toma nota de tal posibilidad, insertando en el art. 59 del Convenio un nuevo apartado, según el cual «2. L'Union européenne peut adhérer á la présente Convention").

Hasta ahora, en todo caso, ya es evidente en múltiples disposiciones (y asimismo en el preámbulo de la Carta, donde se evoca la jurisprudencia del TEDH) la voluntad de intentar evitar los conflictos con el Tribunal de Estrasburgo (en este sentido, además del recientemente citado art. II-113, va el art.II-112, apartado 3, que, retomando el art. 52.3 de 
la Carta de Niza establece: "En la medida en que la presente Carta contenga derechos que correspondan a derechos garantizados por el Convenio Europeo para la Protección de los Derechos Humanos y de las Libertades Fundamentales, su sentido y alcance serán iguales a los que les confiere dicho Convenio. Esta disposición no obstará a que el Derecho de la Unión conceda una protección más extensa»).

Este conjunto complejo de disposiciones (es necesario mencionar también el art. I-112, apartado 4, y el apartado 6, que representan una innovación respecto a la Carta de Niza, según los cuales, respectivamente, "En la medida en que la presente Carta reconozca derechos fundamentales resultantes de las tradiciones constitucionales comunes a los Estados miembros, dichos derechos se interpretarán en armonía con las citadas tradiciones" [apartado 4] y "Se tendrán plenamente en cuenta las legislaciones y prácticas nacionales según lo especificado en la presente Carta" [apartado 6]) es testimonio de un esfuerzo por definir parámetros interpretativos vinculantes para toda autoridad judicial, para evitar dobles estándares.

El Convenio, las tradiciones constitucionales y las legislaciones y prácticas nacionales, son un cemento para construir el Derecho europeo en la materia. En la medida en que las interpretaciones de los derechos fundamentales tienden a adecuarse en los Estados a la doctrina del TEDH (como las legislaciones nacionales), y lo mismo parece resultar de la praxis jurisprudencial luxemburguesa, el CEDH, con el contenido que del mismo resulta a la luz de la doctrina del TEDH, puede convertirse en el fundamento de la sintonía Estados (Tribunales Constitucionales)-Unión (TJUE). Las explicaciones de la Carta sirven al mismo propósito, vinculando a los Tribunales de la Unión y de los Estados miembros. No obstante, no está exenta de riesgos esta obsesiva voluntad de la autoridad normativa por embridar al intérprete judicial (y sólo al judicial va dirigida la regla ex art. II-112.7 TCE) (A. Saiz-Arnaiz 2005).

En definitiva, las normas sobre la interpretación se orientan a reducir las posibilidades de conflicto entre los jueces de los derechos que operan en el sistema multilevel europeo.

En este contexto podrá desempeñar un papel esencial también la cuestión prejudicial: la utilización de esta técnica por parte de los Tribunales constitucionales incentivará el diálogo con la Tribunal de Justicia y contribuirá a influir sobre su jurisprudencia. La Corte costituzionale italiana y el Tribunal constitucional alemán, por lo demás, a diferencia del Tribunal constitucional austríaco o de la Cour d'arbitrage belga, del Tribunal constitucional portugués y del Tribunal constitucio- 
nal polaco, no parece llevar intención de proceder en tal sentido: parecen más orientados a solicitar al juez ordinario la remisión de cuestiones prejudiciales. Una lectura análoga se ha formulado (Saiz Arnaiz 2005) por la STC 58/2004 del Tribunal constitucional español, en la cual se considera parte del derecho a un justo proceso la remisión por parte del juez de la cuestión prejudicial a Luxemburgo, cuando esto resulte obligatorio en el sentido del art. 234 Tratado CE.

El rechazo a elevar cuestiones prejudiciales parece explicarse esencialmente con el temor de perder el propio papel de supremos intérpretes de la Constitución, y de encontrarse por tanto sometidos a las decisiones del Tribunal de Justicia, a los ojos del cual están obligados, con base en el art. 234, apartado 3, Tratado CE, a plantear la cuestión prejudicial, en cuanto jueces cuyas decisiones no son susceptibles de impugnación a nivel nacional. Una hipótesis radical de conflicto se presentaría de aplicarse la doctrina Köbler (STJCE de 30 de septiembre de 2003) a resultas del no-planteamiento por un Tribunal Constitucional de una cuestión prejudicial.

Come se ha subrayado (A. Saiz Arnaiz 2005), el uso de la técnica prejudicial por los Tribunales Constitucionales provocaría efectos muy positivos para la búsqueda de una sintonía con el TJCE. Al elevar la prejudicial, el Tribunal Constitucional podría facilitar al TJ los datos resultantes de la propia Constitución adelantando, en su caso y más o menos explícitamente, el contenido indisponible del derecho fundamental implicado, siempre en perspectiva constitucional $y$, por qué no, a luz también de la jurisprudencia del TEDH. Esto es, sugiriendo al Tribunal de Luxemburgo la interpretación constitucionalmente intolerable y dejando abierta cualquier otra. La respuesta que cabría esperar en tales circunstancias del Tribunal de Justicia sólo podría ser respetuosa con los parámetros facilitados por el Tribunal Constitucional. A ello obligarían, además, algunas de las disposiciones horizontales de la Carta: art. II-112, apartados 3, 4 y 6 y art. II-113.

Al contrario, no existe un mecanismo análogo a la cuestión prejudicial que permita resolver eventuales conflictos interpretativos entre Estrasburgo y Luxemburgo. En este caso, la adhesión de la UE al CEDH comportaría como necesaria consecuencia la adecuación de la jurisprudencia del Tribunal de Justicia a la del TEDH.

Pero, me parece que - con el objetivo de desarrollar un diálogo entre los diversos y múltiples Tribunales de los derechos en Europaexisten, y están ya desde hace años disponibles para operar, instrumentos más eficaces de los positivamente previstos por el ordenamiento (o introducibles en él). Nos referimos a las reuniones informa- 
les, a las conferencias, a los encuentros de estudio, a los coloquios que reúnen tantas veces al año a los «jueces de los derechos". Coloquios horizontales, de los Tribunales constitucionales nacionales (todos o sólo algunos), verticales (entre un Tribunal concreto y los Tribunales de Estrasburgo y Luxemburgo), entre las Tribunales de Estrasburgo y Luxemburgo; más o menos formalizados (en cuanto a su periodicidad); sobre temas generales o cuestiones específicas; simples visitas de estudio, que involucran, además de a los jueces, también a los asistentes y al staff.

Un trabajo subterráneo, poco visible, cuyos frutos son, sin embargo, tangibles en la motivación de las decisiones. Es a partir de este diálogo, una suerte de soft law jurisprudencial, como está naciendo, hace ya muchos años (y por tanto bastante antes de que surgiese la misma hipótesis de una Constitución europea) un orden constitucional común en Europa, fundado sobre una cultura constitucional integrada cada vez en mayor medida.

\section{REFERENCIAS BIBLIOGRÁFICAS}

CARTABIA, M., "Unità nella diversità": il rapporto tra la costituzione europea e le costituzioni nazionali, en www.giustamm.it 2005.

CARTABIA, M., La scrittura di una Costituzione europea e i poteri dei giudici, en www.astridonline.it 2004.

CARTABIA, M., Weiler, J., L'Italia in Europa, Bolonia, II mulino, 2000.

Celotto, A., Groppl, T., "Diritto UE e diritto nazionale: primauté vs. controlimiti», en Riv.it.dir.pubbl.com, 2004, 1309 ss.

Celotto, A., Pistorio, G., "L'efficacia giuridica della Carta dei diritti fondamentali dell'Unione europea (rassegna giurisprudenziale 20012004)", en Giur.it., 2005, 427 ss.

FAVOREU, L., "I garanti dei diritti fondamentali europei», en G. Zagrebelsky (coord.), Diritti e Costituzione nell'Unione europea, Laterza, Bari, 2004, 247 ss.

Gambino, S., "Diritti fondamentali europei e Trattato costituzionale», en Astrid Rassegna, n. 1 de 28 de enero de 2005.

GrIMm, D., "Il significato della stesura di un catalogo europeo dei diritti fondamentali nell'ottica della critica dell'ipotesi di una Costituzione europea", en G. Zagrebelsky (coord.): Diritti e Costituzione nell'Unione europea, Laterza, Bari, 2004, 5 ss. 
Manzella, A., "Dal mercato ai diritti», en AA.VV., Riscrivere i diritti in Europa, II Mulino, Bologna, 2001, 29 ss.

PACIOTTI, E., "La Carta: i contenuti e gli autori", en AA.VV., Riscrivere i diritti in Europa, Bologna, II Mulino, 2001, 9 ss.

Pinelul, C., Il momento della scrittura. Contributo al dibattito sulla costituzione europea, Bologna, II Mulino, 2002.

Pizzorusso, A., Il patrimonio costituzionale europeo, Bologna, II Mulino, 2002.

Rallo Lombarte, A., "Las garantías jurisdiccionales de los Derechos Fundamentales reconocidos en la Carta de Derechos Fundamentales de la Unión Europea", en E. Álvarez Conde, V. Garrido Mayol (coords.), Comentarios a la Constitución Europea, Tirant Lo Blanch, Valencia, 2004, vol. II, 1629 ss.

Rombolı, R., "Carta europea dei diritti e garanzie giurisdizionali (notazioni introduttive)", en AA.VV., Riflessi della Carta europea dei diritti sulla giustizia costituzionale: Italia e Spagna a confonto, Giuffré, Milano, 2003, 107 ss.

SaIz-ARnalz, A., "The Role of Constitutional Courts and the Protection of Fundamental Rights", en AA.VV., Constitución europea y Constituciones nacionales, a cura di M. Cartabia-B. De Witte-P.-Pérez Tremps, Valencia, Tirant lo Blanch, 2005.

VIDAL Prado, C., El impacto del nuevo derecho europeo en los tribunales constitucionales, Madrid, Colex, 2004.

WEILER, J. H. H. (1), "Federalismo e costituzionalismo: il "sonderweg" europeo", en La costituzione dell'Europa, Bologna, II Mulino, 2003

WEILER, J. H. H. (2), "Diritti humanos, costituzionalismo e integrazione: inconografie e feticismo", en Quad. costit., 2003, n. 2

ZILLER, J., La Costituzione europea, Bologna, II Mulino, 2004. 